DISTRIBUTION STATEMENT A. Approved for public release; distribution is unlimited.

\title{
SST Control by Subsurface Mixing during Indian Ocean Monsoons
}

\author{
Emily Shroyer \\ CEOAS, Oregon State University \\ 104 CEOAS Administration Building \\ Corvallis, OR 97331-5503 \\ phone: 5417371298 \\ email: eshroyer@coas.oregonstate.edu \\ James Moum \\ CEOAS, Oregon State University \\ 104 CEOAS Administration Building \\ Corvallis, OR 97331-5503 \\ phone: 5417372553 \\ email:moum@coas.oregonstate.edu
}

Award Number: N00014-14-1-0236

\section{LONG-TERM GOALS}

We seek to understand the detailed evolution of heat and freshwater distributions in the Bay of Bengal, given large-scale gradients associated with forcing (e.g., large source of freshwater input, heat fluxes, and wind forcing) and small-scale mixing processes. Since sea surface temperature variations are broad spatially and vary over long time scales, we are using extended time series at a variety of locations to directly measure and assess SST modification by turbulent mixing over the broad expanse of international waters in the Bay of Bengal on diurnal to seasonal time scales.

\section{OBJECTIVES}

Our specific objectives are to:

1. quantify the variability in upper ocean mixing associated with changes in barrier layer thickness and strength across the BoB and under different forcing conditions,

2. quantify the subsurface heat flux divergence across the thermocline and through the barrier layer that contributes to changes in SST, and

3. contrast barrier layer character (e.g., maintenance, turbulent mixing, strength) associated with relatively weak but uniform freshwater pools (e.g., originating from distant storms and/or riverine sources) to that of strong, patchy pools created through local precipitation.

These objectives directly target the fundamental role that upper ocean dynamics play in the complex air-sea interactions of the northern Indian Ocean. 


\section{Report Documentation Page}

Form Approved

OMB No. 0704-0188

Public reporting burden for the collection of information is estimated to average 1 hour per response, including the time for reviewing instructions, searching existing data sources, gathering and maintaining the data needed, and completing and reviewing the collection of information. Send comments regarding this burden estimate or any other aspect of this collection of information,

including suggestions for reducing this burden, to Washington Headquarters Services, Directorate for Information Operations and Reports, 1215 Jefferson Davis Highway, Suite 1204, Arlington

VA 22202-4302. Respondents should be aware that notwithstanding any other provision of law, no person shall be subject to a penalty for failing to comply with a collection of information if it

does not display a currently valid OMB control number.

1. REPORT DATE

30 SEP 2014

4. TITLE AND SUBTITLE

SST Control by Subsurface Mixing during Indian Ocean Monsoons

6. $\operatorname{AUTHOR}(\mathrm{S})$

7. PERFORMING ORGANIZATION NAME(S) AND ADDRESS(ES)

Oregon State University, College of Earth, Ocean, and Atmospheric Sciences,104 CEOAS Administration Building,Corvallis,OR,97331-5503

9. SPONSORING/MONITORING AGENCY NAME(S) AND ADDRESS(ES)

12. DISTRIBUTION/AVAILABILITY STATEMENT

Approved for public release; distribution unlimited

13. SUPPLEMENTARY NOTES

14. ABSTRACT

15. SUBJECT TERMS

16. SECURITY CLASSIFICATION OF:

a. REPORT

unclassified b. ABSTRACT

unclassified c. THIS PAGE

unclassified
17. LIMITATION OF ABSTRACT

Same as

Report (SAR)
3. DATES COVERED

00-00-2014 to 00-00-2014

5a. CONTRACT NUMBER

5b. GRANT NUMBER

5c. PROGRAM ELEMENT NUMBER

5d. PROJECT NUMBER

5e. TASK NUMBER

5f. WORK UNIT NUMBER

8. PERFORMING ORGANIZATION

REPORT NUMBER

10. SPONSOR/MONITOR'S ACRONYM(S)

11. SPONSOR/MONITOR'S REPORT

NUMBER(S) 


\section{APPROACH}

In short, our approach has been to augment as many platforms as possible with additional turbulence

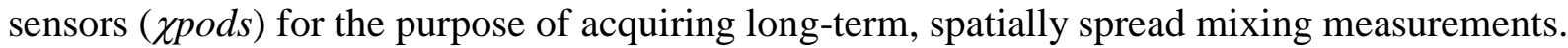
Specifically, we have

1) deployed 10 xpods on NRL moorings in the BoB (to be recovered summer 2015),

2) augmented the $12 \mathrm{~N}$ RAMA mooring with $\chi$ pods at 15 and $30 \mathrm{~m}$ depth (to be recoverd fall 2014),

3) equipped Revelle and Sagar Nidhi CTDs with self-contained $\chi p$ pods during survey work in winter 2013,

4) constructed and shipped 9 xpods for deployment at 15, 30, and 45 meters on each of the 8, 12, and 15 N RAMA moorings for deployment fall 2014 (to be recovered fall 2015), and

5) constructed and shipped 6 xpods for deployment on the WHOI air-sea interaction mooring at $18 \mathrm{~N}$ in fall 2014 (to be recovered fall 2015).

PI Shroyer has taken part in both shipboard field seasons. Analysis from these efforts is underway. We are eagerly awaiting the return of the first moored time series.

\section{WORK COMPLETED}

Construction of new $\chi$ pods and refurbishment of existing units have now been completed. All $\chi$ pods are either currently in the water (12 N RAMA and NRL systems) or en route to deployment sites (other RAMA and WHOI mooring systems). A map summarizing existing and upcoming mixing measurements is shown in Figure 1. Moored data should start to arrive this fall with the turn around of the 12 N RAMA mooring.

The PI has participated in two ASIRI field cruises- November-December 2013 and June 2014. She was the lead Chief Scientist for the winter cruise and assisted in the sumer 2014 cruise. CTD- $\chi$ pod measurements were acquired throughout the 2013 cruise; and $\chi$ pods were added to wirewalkers for the summer 2014 work. 


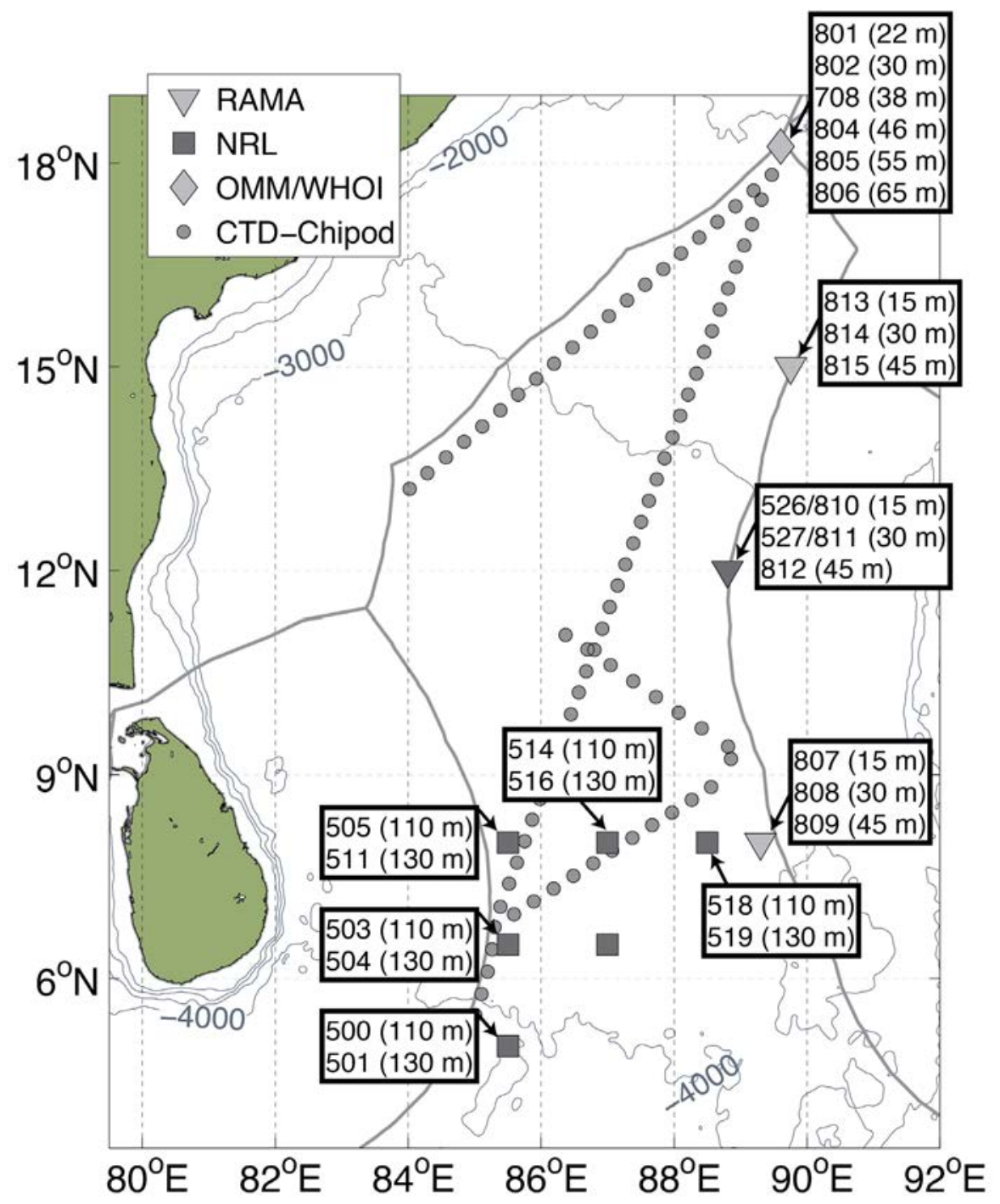

Figure 1: Map of existing (dark grey) and upcoming (light grey) xpod deployments on moorings (RAMA-triangles, NRL-squares, and WHOI/OMM-diamond). CTD- Xpod stations that were collected during the 2013 pilot are indicated by circles. The RAMA mooring at $12 N$ will collect a two-year data record with turn-around this fall. All other locations will span periods of 12-18 months. 


\section{RESULTS}
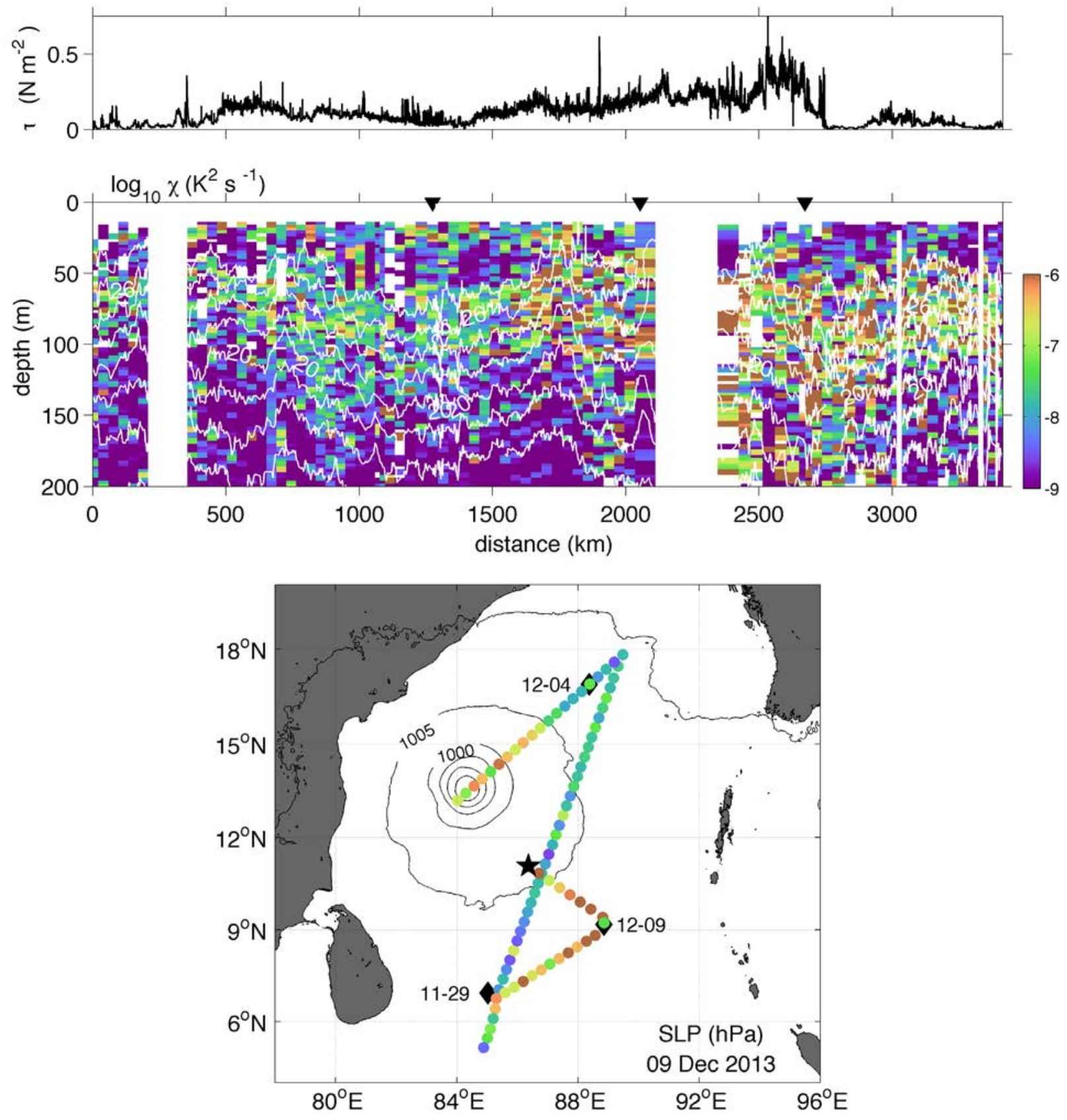

Figure 2: Wind stress as measured from the ship (upper panel), temperature variance dissipation rate (lower panel), and sea level pressure (courtesy Rashmi Sharma and Prashant Kumar) with average temperature variance dissipation in color (map). 
CTD- $\chi$ pod data and turbulence glider measurements (Louis St. Laurent, WHOI) are being used to assess the mixing footprint of Cyclone Madi, a storm that developed and intensified during the 2013 cruise (Fig. 2). Mixing within the thermocline was relatively weak during the northward transit, and began to intensify (along with winds) during the southwest transit outside the Indian EEZ.

Wind and wave conditions over the northern portion of the southeast leg along with increasing urgency to recover a turbulence glider (star, Fig. 2), prohibited additional CTD profiling during the first portion of the southeast leg. The maximum mixing was observed more than $500 \mathrm{~km}$ from the center of the storm during its peak intensity. We are in the process of anlalyzing the inertial wave response using shipboard ADCP data and the local mixing response using turbulence glider data in conjunction with Louis St. Laurent (WHOI).

Upon return of the moored data we plan on assessing the monsoonal mixing signals and implication for upper ocean heat budget/air-sea fluxes. We will also look at the higher wavenumber and frequency mixing signals using $\chi$ pods deployed on the NRL mooring array, (e.g., internal wave signals and dynamics associated with the Sri Lankan dome).

\section{IMPACT/APPLICATIONS}

Within the Bay of Bengal high freshwater input creates salt-stratification that can form a barrier layer, dynamically isolating the thermocline from the surface mixed layer and trapping atmospheric heat and momentum fluxes near the surface. This buoyancy flux further stabilizes near-surface layers, therby requiring an increase in the energy needed to mix cool fluid up from the thermocline. Our work seeks to understand the time-evolving contribution of mixing to the upper ocean heat budget and sea surface temperature under the influence of strong freshwater buoyancy forcing and monsoonal winds.

\section{PUBLICATIONS}

A. J. Lucas and E. L. Shroyer and H. W. Wijesekera and H. J. S. Fernando and E. D'Asaro and M. Ravichandran and S. U. P. Jinadasa and J. A. MacKinnon and J. D. Nash and R. Sharma and L. Centurioni and J. T. Farrar and R. Weller and R. Pinkel and A. Mahadevan and D. Sengupta and A. Tandon, Eos, Transactions American Geophysical Union 95 269--270 (2014)

\section{RELATED PROJECTS}

N00014-13-1-0357 funded the pilot work for this project. 